\title{
High-resolution Manometry Findings During Solid Swallows Correlate With Delayed Reflux Clearance and Acid Exposure Time in Non-erosive Reflux Disease Patients
}

\author{
Mentore Ribolsi, ${ }^{*}$ Dario Biasutto, Antonio Giordano, Paola Balestrieri, and Michele Cicala \\ Unit of Digestive Disease, Campus Bio Medico University of Rome, Italy
}

\section{Background/Aims}

The role of esophageal motility in determining gastroesophageal reflux disease (GERD) severity has not been completely evaluated. A few studies have investigated high-resolution manometry (HRM) patterns during solid swallows. The present study evaluates the HRM patterns of non-erosive reflux disease (NERD) patients during both liquid and solid swallows and their correlation with the severity of GERD.

\section{Methods}

In 23 NERD patients and 15 healthy volunteers (HVs) HRM was performed during a standard solid meal in a seated position, followed by 24-hour impedance-pH monitoring.

\section{Results}

Of the 31 patients, 10 showed a pathological acid exposure time (AET; NERD patients), 13 a normal pH profile with positive symptom association probability (SAP; reflux hypersensitivity patients), and 8 normal AET and SAP (functional heartburn patients). Mean distal contractile integral and distal latency values, in all patient groups and HVs, were significantly higher during solid swallows. In the group of 10 NERD patients, the number of large breaks of the esophageal peristalsis was 16 out of 100 liquid swallows (16\%) and 31 out of 171 solid swallows (18\%). Fourteen out of 100 liquid swallows (14\%) and 25 out of 171 solid swallows (15\%) resulted ineffective. Mean reflux clearing time at multichannel intraluminal impedance-pH was $17.6 \pm 3.7$ seconds. NERD patients presented, during solid swallows, a significantly higher proportion of large peristaltic breaks and of ineffective swallows than reflux hypersensitivity and functional heartburn patients.

\section{Conclusion}

HRM during solid swallows reveals motor abnormalities, undetected during liquid swallows, which might be involved in delaying reflux and acid clearance in patients with GERD.

(J Neurogastroenterol Motil 2019;25:68-74)

Key Words

Esophageal sphincter, lower; Gastroesophageal reflux; Manometry; Peristalsis; Swallows

Received: March 13, 2018 Revised: June 28, 2018 Accepted: September 13, 2018

(.) This is an Open Access article distributed under the terms of the Creative Commons Attribution Non-Commercial License (http://creativecommons. org/licenses/by-nc/4.0) which permits unrestricted non-commercial use, distribution, and reproduction in any medium, provided the original work is properly cited.

*Correspondence: Mentore Ribolsi, MD, PhD Unit of Digestive Disease, Campus Bio Medico University of Rome, Via Alvaro del Portillo 200, 00128 Rome, Italy Tel: +39-06-225411, Fax: +39-06-22541-520, E-mail: m.ribolsi@unicampus.it 


\section{Introduction}

GERD patients may present delayed bolus transit as well as delayed esophageal reflux clearance, due to impaired esophageal peristalsis. ${ }^{1,2}$ It has been largely demonstrated that GERD patients frequently show ineffective esophageal motility (IEM), described as low amplitude peristaltic waves $(<30 \mathrm{mmHg}$ ) at the distal esophagus and/or non-transmitted proximal contractions, although its role in esophageal function has not been elucidated yet. ${ }^{3,4}$

An impaired esophageal function has been postulated to be the cause or the result of esophageal mucosal damage. ${ }^{5-7}$ Moreover, although a correlation between IEM and prolonged esophageal acid exposure time (AET) has been demonstrated, only severe IEM may result in prolonged esophageal clearance and abnormal AET in GERD patients. ${ }^{8}$ The use of high-resolution manometry (HRM), improving the knowledge of esophageal motility, has become the gold standard for the diagnosis of esophageal motor disorders. Moreover, HRM may be coupled with multichannel impedance monitoring to simultaneously record and analyse esophageal motility and bolus transit. It has been demonstrated that large breaks in esophageal peristalsis, observed at HRM, seem to have an impact on typical symptoms as well as on cough elicitation, delaying bolus clearance, and, conceivably, reflux clearing time (RCT). ${ }^{9,10}$ However, whether the impairment of esophageal motility may impact on GERD severity has not been fully explained.

Normative HRM values have been acquired with a 36-channel solid state catheter and asymptomatic controls have been analysed in the supine position while swallowing ten $5 \mathrm{~mL}$ water boluses. ${ }^{11,12}$ These values represent the milestone in the analysis of HRM tracings but some limitations hamper their clinical utility. Liquid boluses, during both conventional and HRM, are swallowed in the supine position, which does not reflect the physiological condition. Moreover, swallowing small $(5 \mathrm{~mL})$ volume of water might not always trigger symptoms.

A multiple rapid swallows test has been recently proposed to assess the peristaltic reserve during HRM. ${ }^{13}$ This test consists of 5 swallows in rapid sequence and, in normal conditions, is associated with an inhibition of the esophageal peristalsis and a marked LES relaxation. Usually, the the last swallow is followed by a pronounced esophageal contraction. Abnormal responses consist of an incomplete inhibition with residual peristaltic activity and/or suboptimal contraction. Finally, it has been demonstrated that during multiple rapid swallows the amplitude of peristalsis and AET correlate inversely in patients with non-erosive reflux disease (NERD). ${ }^{14}$
Data on HRM patterns during solid swallows are limited. It is conceivable that solid swallows, more than liquid or viscous ones, although not standardised, could potentially unmask peristaltic failures.

The aim of the present study is, therefore, to explore the peristaltic pattern in NERD patients performing HRM during conventional liquid and solid swallows, by means of a solid meal, and to investigate their possible association with severity of reflux disease.

\section{Materials and Methods}

\section{Study Design}

GERD patients were recruited from the outpatient gastrointestinal unit between January 2014 and January 2016, all presenting recurrent ( $\geq 2$ /week) typical GERD symptoms - heartburn and/ or regurgitation, lasting for $>6$ months and responding to a proton pump inhibitors (PPIs) treatment for at least 4 weeks. All patients underwent upper endoscopy, performed after washout ( $>1$ month) from PPIs and/or histamine $\mathrm{H} 2$ receptor antagonists, and those who were diagnosed with hiatal hernia and esophageal erosions were excluded.

Among the screened patients, 34 (15 female; mean age 41, range 27-58 years) of them were enrolled. All patients filled out a standardized questionnaire (Reflux Disease Questionnaire) ${ }^{15}$ and underwent HRM combined with multichannel impedance (HRM-MI) followed by 24-hour multichannel intraluminal impedance-pH (MII-pH) monitoring, performed in the same day. The HRM-MI study included a preliminary manometry with conventional liquid swallows followed by a standard meal, eaten within 20 minutes. Patients with motility disorders, according to the Chicago classification version 3.0, were excluded. ${ }^{16}$

Fifteen asymptomatic healthy volunteers (HVs) (6 female; mean age 25, range 20-42 years), matched for age, sex, and body mass index, underwent 24-hour MII-pH and HRM-MI. All HVs filled out the Reflux Disease Questionnaire for reflux disease. Written informed consent was obtained from all individuals enrolled.

\section{High-resolution Manometry Combined With Multichannel Impedance}

A catheter with 36 circumferential solid state pressure sensors, located at $1-\mathrm{cm}$ intervals, and 8 impedance measuring segments with a 2-cm separation (high-resolution impedance manometry; Medical Measurement Systems, Enschede, The Netherlands) 
was used. The catheter was placed in the upright, seated position with at least 3 distal pressure sensors positioned in the stomach, and the distal impedance measuring segment at $5 \mathrm{~cm}$ above the lower esophageal sphincter (LES). A preliminary manometric study was performed, with 10 saline $(5 \mathrm{~mL})$ swallows, at 30-second intervals, in each individual, in a semi-recumbent position. Subsequently, subjects were asked to eat a standard solid meal (a $13 \mathrm{~cm} \times 13 \mathrm{~cm}$ $\times 3 \mathrm{~cm}$ toast with ham, about $320 \mathrm{kcal}$ ) within 20 minutes in the seated position. All individuals were instructed to eat normally.

\section{4-Hour Multichannel Intraluminal Impedance-pH}

The MII-pH probe (Sandhill Scientific, Highlands Ranch, CO, USA) was positioned after MI- HRM, with the $\mathrm{pH}$ electrode $5 \mathrm{~cm}$ above the LES and impedance was measured at 3, 5, $7,9,15$, and $17 \mathrm{~cm}$ above the LES. Patients were asked not to lie down during the daytime, but only at their usual bedtime, and were instructed to have 3 standard meals at fixed times. Event markers recorded occurrence of symptoms, times of meals, and changes in posture.

\section{Data Analysis}

\section{High-resolution manometry combined with multichannel impedance}

Data were analyzed using a dedicated software. The presence of motility disorders were assessed analyzing the tracings of preliminary HRM-MI studies with 10 saline swallows, according to the Chicago v3.0 classification. ${ }^{16}$

For both liquid swallows and the solid swallows during the meal, the 4-second integrated relaxation pressure, as well as the distal contractile integral (DCI) and distal latency (DL) values were calculated. Both liquid and solid swallows were defined as failed (DCI < $100 \mathrm{mmHg} \cdot \mathrm{sec} \cdot \mathrm{cm}$ ) or weak (DCI > $100 \mathrm{mmHg} \cdot \mathrm{sec} \cdot \mathrm{cm}$ but $<450 \mathrm{mmHg} \cdot \mathrm{sec} \cdot \mathrm{cm}$ ). Weak or failed swallows were finally defined as ineffective. A liquid or solid swallows presenting a large break (length $>5 \mathrm{~cm}$ ) in the $20-\mathrm{mmHg}$ isobaric contour with DCI $>450 \mathrm{mmHg} \cdot \mathrm{sec} \cdot \mathrm{cm}$ was defined fragmented. Esophageal bolus clearance was evaluated, during liquid and solid swallows, measuring the total bolus transit time (TBTT). TBTT represents the time required by the bolus to pass through the whole esophagus, ie, the time elapsing between bolus entry in the proximal impedance recording segment and bolus exit from the most distal recording segment.

\section{4-Hour multichannel intraluminal impedance-pH}

Reflux events were detected and classified according to published criteria. ${ }^{17}$ AET was defined as pathological if the time at $\mathrm{pH}<4$ exceeded $5 \%$ of the total recording time. Reflux episodes reaching the sensor at $15 \mathrm{~cm}$ above the LES were defined as proximal. The symptom association probability (SAP) for all reflux episodes was calculated according to the formula described elsewhere. ${ }^{17}$ Heartburn and regurgitation were considered in the analysis of symptoms. Reflux episodes were classified as symptom-related if they occurred $\leq 2$ minutes before the onset of the symptom. RCT, ie, time-frame between reflux entry and exit, was calculated at 5, 9, and $15 \mathrm{~cm}$ above the LES, after a manual analysis of each MII-pH tracing.

\section{Statistical Methods}

Data are presented as mean and standard deviation of the mean or mean and range. Mean values between patients group and $\mathrm{HVS}$ were compared using ANOVA. Fisher's exact test was used to compare differences between proportions. Differences were judged statistically significant with $P<0.05$. The statistical analysis was performed using SPSS software (version 16; IBM Corp, Armonk, NY, USA).

\section{Results}

Of the 34 NERD patients enrolled, 2 patients presented evidence of IEM and 1 of failed peristalsis and were, therefore, not considered for the analysis. Therefore, 31 patients and $15 \mathrm{HVs}$ were analyzed.

\section{Multichannel Intraluminal Impedance-pH Results}

Of the 31 patients, 10 showed a pathological AET (mean 8.2\%, range 5.4-16.1\%) (NERD patients), 13 a normal $\mathrm{pH}$ profile (mean $1.7 \%$, range $0.4-2.8 \%$ ) with positive SAP (reflux hypersensitivity $[\mathrm{RH}]$ patients) and 8 both normal AET and SAP (functional heartburn $[\mathrm{FH}]$ patients). All $15 \mathrm{HVs}$ displayed a normal acid exposure (mean $1.6 \%$, range $0.7-2.4 \%$ ). Compared to the HVs, NERD, and RH patients showed a significantly higher mean number of reflux episodes as well as a higher proportion of acid and proximal reflux episodes. The percentage of mixed reflux episodes was similar between the patients and HVs (Table 1).

\section{High-resolution Manometry Results}

Patients and $\mathrm{HV}$ s performed a total of 310 and 150 liquid swal- 
lows, respectively. During the meal, patients and HVs performed a total of 521 and 174 swallows, respectively.

Mean DCI, DL, and IRP values are in Table 2. Mean DCI and DL values, in all patient groups and $\mathrm{HV}$ s, were significantly higher during solid swallows. Mean TBTT value, assessed during liquid swallows, was similar between patients and HVs $(8.4 \pm 2.1$ seconds in NERD patients, $7.8 \pm 1.8$ seconds in RH patients, and $7.9 \pm 1.7$ seconds in $\mathrm{FH}$ patients vs $7.8 \pm 2.4$ seconds in $\mathrm{HV}$ s; $P=$ NS). During solid swallows, mean TBTT value was higher in only NERD patients compared to HVs $(12.2 \pm 4.4$ seconds and $10.4 \pm 3.2, P=0.070$ ), although this difference did not reach statistical significance. In the group of 10 NERD patients, the proportion of large breaks of the esophageal peristalsis was 16 out of 100 liquid swallows (16\%) and 31 out of 171 solid swallows (18\%). Fourteen out of 100 liquid swallows (14\%) and 25 out of 171 solid swallows (15\%) were ineffective (Figure). Mean RCT at MII$\mathrm{pH}$ was $17.6 \pm 3.7$ seconds. In the group of $13 \mathrm{RH}$ patients, the proportion of large breaks of the esophageal peristalsis was 17 out of 130 (13\%) ( $P=$ NS vs NERD patients) liquid swallows and 18 out of 206 (9\%) solid swallows ( $P<0.05$ vs NERD patients). Thirteen out of 130 liquid swallows $(10 \%)(P=$ NS vs NERD patients) and 16 out of 202 solid swallows $(8 \%)(P<0.05$ vs NERD patients) were ineffective. Mean RCT at MII-pH was
$12.8 \pm 2.3$ seconds $(P<0.05$ vs NERD patients). In the group of $8 \mathrm{FH}$ patients, the proportion of large breaks of the esophageal peristalsis was 11 out of $80(14 \%)$ ( $P=\mathrm{NS}$ vs NERD patients) liquid swallows and 12 out of $144(8 \%)$ solid swallows $(P<0.05$ vs NERD patients). Nine out of 80 liquid swallows $(11 \%)(P=\mathrm{NS}$

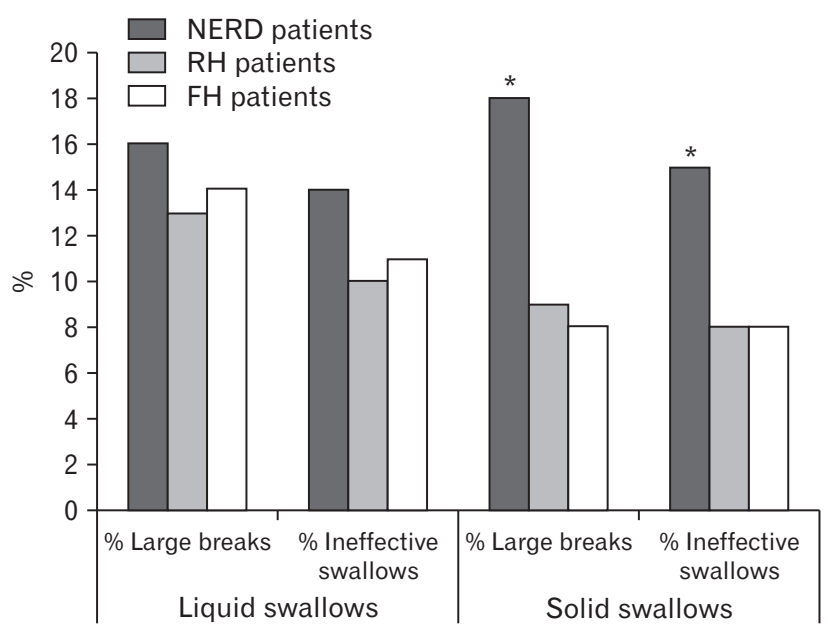

Figure. Proportion of peristaltic breaks and of ineffective swallows during high-resolution manometry with liquid and solid swallows. ${ }^{*}<$ 0.05 vs reflux hypersensitivity $(\mathrm{RH})$ and functional heartburn $(\mathrm{FH})$ patients. NERD, non-erosive reflux disease.

Table 1. Multichannel Intraluminal Impedance-pH Monitoring Findings in Non-erosive Reflux Disease Patients and Healthy Volunteers

\begin{tabular}{llccc}
\hline & $\begin{array}{c}\text { HVs } \\
(\mathrm{n}=15)\end{array}$ & $\begin{array}{c}\text { NERD patients } \\
(\mathrm{n}=10)\end{array}$ & $\begin{array}{c}\text { RH patients } \\
(\mathrm{n}=13)\end{array}$ & $\begin{array}{c}\text { FH patients } \\
(\mathrm{n}=8)\end{array}$ \\
\hline Total reflux episodes & $33 \pm 8$ & $52 \pm 15^{\mathrm{a}}$ & $58 \pm 18^{\mathrm{a}}$ & $39 \pm 8$ \\
Acid & $28 \pm 8 \%$ & $61 \pm 18 \%^{\mathrm{a}}$ & $35 \pm 7 \%$ & $24 \pm 7 \%$ \\
Mixed & $42 \pm 8 \%$ & $42 \pm 10 \%$ & $45 \pm 12 \%$ & $43 \pm 11 \%$ \\
Proximal & $34 \pm 4 \%$ & $52 \pm 10 \%^{\mathrm{a}}$ & $48 \pm 10 \%^{\mathrm{a}}$ & $47 \pm 9 \%$ \\
\hline
\end{tabular}

${ }^{\mathrm{a}} \mathrm{P}<0.05$ vs healthy volunteers ( $\mathrm{HVs}$ ).

NERD, non-erosive reflux disease; RH, reflux hypersensitivity; FH, functional heartburn.

Data are expressed as mean $\pm \mathrm{SD}$.

Table 2. High-resolution Manometry Findings in Non-erosive Reflux Disease Patients and Healthy Volunteers

\begin{tabular}{lccc}
\hline & $\begin{array}{c}\text { DCI } \\
\text { (solid/liquid) }\end{array}$ & $\begin{array}{c}\text { DL } \\
\text { (solid/liquid) }\end{array}$ & $\begin{array}{c}\text { IRP } \\
\text { (solid/liquid) }\end{array}$ \\
\hline NERD Patients & $1487 \pm 311^{\mathrm{a}} / 872 \pm 213$ & $8.4 \pm 1.2^{\mathrm{b}} / 6.2 \pm 0.3$ & $8.3 \pm 2.2 / 7.4 \pm 1.4 \mathrm{mmHg}$ \\
RH patients & $1685 \pm 546^{\mathrm{a}} / 1044 \pm 324$ & $9.8 \pm 1.8^{\mathrm{b}} / 7.8 \pm 0.4$ & $6.7 \pm 3.4 / 5.3 \pm 2.8 \mathrm{mmHg}$ \\
FH patients & $1783 \pm 456^{\mathrm{a}} / 942 \pm 284$ & $9.4 \pm 1.7^{\mathrm{b}} / 7.4 \pm 0.3$ & $6.6 \pm 3.3 / 5.2 \pm 2.6 \mathrm{mmHg}$ \\
HVs & $1711 \pm 448^{\mathrm{a}} / 1031 \pm 311$ & $8.9 \pm 1.4^{\mathrm{b}} / 6.9 \pm 0.4$ & $8.7 \pm 3.4 / 6.3 \pm 2.7 \mathrm{mmHg}$
\end{tabular}

${ }^{\mathrm{a}} P<0.05,{ }^{\mathrm{b}} P<0.01$.

DCI, distal contractile integral; DL, distal latency; IRP, integrated relaxation pressure; NERD, non-erosive reflux disease; RH, reflux hypersensitivity; FH, functional heartburn; HVs, healthy volunteers. 
vs NERD patients) and 12 out of 144 solid swallows $(8 \%)(P<$ 0.05 vs NERD patients) were ineffective. Mean RCT at MII-pH was $11.7 \pm 1.6$ seconds $(P<0.05$ vs NERD patients). Results are displayed in Figure.

\section{Discussion}

The role of weak esophageal peristalsis in determining the severity of GERD still remains under debate. Several studies have demonstrated that esophageal hypomotility disorders are only partially associated with a delayed bolus transit, both in dysphagic patients and in asymptomatic subjects. Conversely, severe IEM as well as an abnormal number of esophageal peristaltic breaks seem to correlate with prolonged acid and reflux clearance and, hence, to GERD severity.

The introduction of HRM in the diagnostic workup of esophageal motility disorders has led to an improvement in the knowledge of the correlation between reflux disease and esophageal function. However, current the ambulatory HRM is still performed with the same protocol of conventional manometry, ie, by means of 10 liquid swallows. Therefore, it is reasonable to consider this test unable to reveal all potential peristaltic failures that a more severe test could detect. The recent use of the multiple rapid swallows test represents a first step in this direction.

The present study aimed to assess, in a group of NERD patients and healthy subjects, the peristaltic function while swallowing a standardized solid meal, eaten within 20 minutes at each individual's convenience, in a seated position. Therefore, the purpose of performing the HRM during a solid meal was to evaluate the characteristics of the peristaltic waves in a more physiological condition and to correlate them with GERD severity. Up to now, there are few studies available in whom individuals have been evaluated with HRM and solid swallows. ${ }^{18,19}$ Efforts were made to carefully select healthy subjects without evidence of peristaltic disorders and with presence of proven reflux disease, ie, with positive AET and/or SAP.

According to the results reported herewith, in patients and healthy controls, mean DL values were significantly higher during solid swallows. In our series, the mean DCI value was higher during solid in comparison with liquid swallows in the asymptomatic controls and in all groups of patients. These data are in agreement with those by Sweis et $\mathrm{al}^{19}$ who demonstrated in healthy subjects, that contractile vigor was higher during solid swallows. This finding could reasonably be the consequence of the greater peristaltic vigor necessary to clear a solid bolus from the esophagus to the stomach.
However, in the group of NERD patients, ie, of patients with a pathological AET during solid swallows, an increased proportion of large peristaltic breaks and ineffective swallows was detected compared to $\mathrm{HV}_{\mathrm{s}}, \mathrm{RH}$, and $\mathrm{FH}$ patients, whilst no differences were observed during liquid swallows. These results are in agreement with those by Sweis et $\mathrm{al}^{20}$ who explored the esophageal function in GERD patients with HRM during a solid, standard meal. The authors found that GERD patients presented fewer effective swallows compared to asymptomatic subjects and concluded that the detection of dysmotility during a test meal increases the diagnostic yield of esophageal dysfunction in patients presenting with reflux symptoms. ${ }^{20}$

Nowadays, the presence of large peristaltic breaks in more than $50 \%$ of liquid swallows is considered as the cut-off for the diagnosis of fragmented peristalsis, according to the Chicago v3.0 criteria. ${ }^{16}$ This finding correlates with delayed bolus transit and dysphagia perception. It has been demonstrated that large breaks of esophageal peristalsis are associated by a significantly prolonged reflux clearance in the supine position and higher AET in GERD patients with typical symptoms. ${ }^{9}$ Moreover, large breaks of the esophageal peristalsis seem to have an impact on cough elicitation, delaying bolus clearing and, conceivably, reflux clearing. ${ }^{10}$

In the present study, the HRM evaluation during the meal aimed to assess the esophageal motility on more physiological, albeit stressful condition. Reasonably, the assessment of peristaltic efficacy during a meal, even not standardized, might unmask a potential failure of the esophageal function. The increased proportion of breaks and of ineffective swallows during the meal, observed in a subgroup of our patient population, might be associated with a delayed acid and reflux clearing and a prolonged bolus retention into the esophageal lumen. Indeed, in the subgroup of NERD patients, it has been observed (1) a higher mean RCT and (2) a pathological AET, when compared to $\mathrm{RH}$ and $\mathrm{FH}$ patients.

Why are esophageal abnormalities related to GERD unmasked only during a solid meal consumption? Moreover, why are esophageal abnormalities related only to solid meal important for liquid reflux? The answer might be that gastric refluxate could be assumed as a mixture of liquids (swallowed liquids, bile acids, and gastric acid) and gas, with different and unpredictable viscosity and volume, whose clearing is also dependent on the efficacy of the esophageal function. Great volumes of refluxate might be relevant, in terms of peristaltic function, similarly to a bolus of a solid meal. In this scenario, therefore, the presence of peristaltic defects, as only revealed by HRM during a solid meal, may lead to an increased GERD severity, ie, reduced clearing of high-volume reflux epi- 
sodes.

It has been demonstrated that HRM is a novel, promising technique that might be helpful in understanding the relationship between the esophageal motor parameters and GERD, ${ }^{8,921-23}$

The study herewith presented is hampered by some limitations. The small population of patients enrolled does not allow consideration of these conclusions as definitive. A similar study is needed in a larger population. Moreover, the meal test is not standardized and could be influenced by the high variability in swallowing. Finally, a direct correlation between reflux episodes and peristalsis is still lacking.

In conclusion, our study further supports the role of esophageal motility in reflux pathogenesis and encourages the assessment of esophageal function with HRM, performed with both liquid and solid swallows.

\section{Financial support: None.}

\section{Conflicts of interest: None.}

Author contributions: Mentore Ribolsi designed the study, performed the research, analyzed the data, and wrote the paper; Dario Biasutto and Antonio Giordano performed the research, analyzed the data, and wrote the paper; Paola Balestrieri performed the research; and Michele Cicala designed the study and revised the manuscript for final submission.

\section{References}

1. Kahrilas PJ, Dodds WJ, Hogan WJ, Kern M, Arndorfer RC, Reece A. Esophageal peristaltic dysfunction in peptic esophagitis. Gastroenterology 1986;91:897-904.

2. Lemme EM, Abrahão-Junior LJ, Manhães Y, Shechter R, Caevalho $\mathrm{BB}$, Alvariz A. Ineffective esophageal motility in gastroesophageal erosive reflux disease and in nonerosive reflux disease: are they different? J Clin Gastroenterol 2005;39:224-227.

3. Olsen AM, Schlegel JF. Motility disturbances caused by esophagitis. J Thorac Cardiovasc Surg 1965;50:607-612.

4. Leite LP, Johnston BT, Barrett J, Barrett J, Castell JA, Castell DO. Ineffective esophageal motility (IEM): the primary finding in patients with nonspecific esophageal motility disorder. Dig Dis Sci 1997;42:18591965.

5. Zhang X, Geboes K, Depoortere I, Tack J, Janssens J, Sifrim D. Effect of repeated cycles of acute esophagitis and healing on esophageal peristalsis, tone, and length. Am J Physiol Gastrointest Liver Physiol 2005;288:G1339-G1346.

6. Singh P, Adamopoulos A, Taylor RH, Colin-Jones DG. Oesopha- geal motor function before and after healing of oesophagitis. Gut 1992;33:1590-159.

7. Fornari F, Blondeau K, Durand L, et al. Relevance of mild ineffective oesophageal motility (IOM) and potential pharmacological reversibility of severe IOM in patients with gastro-oesophageal reflux disease. Aliment Pharmacol Ther 2007;26:1345-1354.

8. Ribolsi M, Balestrieri P, Emerenziani S, Guarino MP, Cicala M. Weak peristalsis with large breaks is associated with higher acid exposure and delayed reflux clearance in the supine position in GERD patients. Am J Gastroenterol 2014;109:46-51.

9. Almansa C, Smith JA, Morris J, et al. Weak peristalsis with large breaks in chronic cough: association with poor esophageal clearance. Neurogastroenterol Motil 2015;27:431-442.

10. Pandolfino JE, Ghosh SK, Zhang Q, Jarosz A, Shah N, Kahrilas PJ. Quantifying EGJ morphology and relaxation with high-resolution manometry: a study of 75 asymptomatic volunteers. Am J Physiol Gastrointest Liver Physiol 2006;290:G1033-G1040.

11. Pandolfino JE, Fox MR, Bredenoord AJ, Kahrilas PJ. High-resolution manometry in clinical practice: utilizing pressure topography to classify oesophageal motility abnormalities. Neurogastroenterol Motil 2009;21:796-806.

12. Shaker A, Stoikes N, Drapekin J, Kushnir V, Brunt LM, Gyawali CP. Multiple rapid swallow responses during esophageal high-resolution manometry reflect esophageal body peristaltic reserve. Am J Gastroenterol 2013;108:1706-1712.

13. Martinucci I, Savarino EV, Pandolfino JE, et al. Vigor of peristalsis during multiple rapid swallows is inversely correlated with acid exposure time in patients with NERD. Neurogastroenterol Motil. 2016;28:243-250.

14. Shaw MJ, Talley NJ, Beebe TJ, et al. Initial validation of a diagnostic questionnaire for gastroesophageal reflux disease. Am J Gastroenterol 2001;96:52-57.

15. Kahrilas PJ, Bredenoord AJ, Fox M, et al. The Chicago classification of oesophageal motility disorders, v3.0. Neurogastroenterol Motil 2015;27:160-174.

16. Sifrim D, Castell D, Dent J, Kahrilas PJ. Gastro-oesophageal reflux monitoring: review and consensus report on detection and definitions of acid, non-acid, and gas reflux. Gut 2004;53:1024-1031.

17. Weusten BL, Roelofs JM, Akkermans LM, Van Berge-Henegouwen GP, Smout AJ. The symptom-association probability: an improved method for symptom analysis of 24-hour esophageal $\mathrm{pH}$ data. Gastroenterology 1994;1071:1741-1745.

18. Bogte A, Bredenoord AJ, Oors J, Siersema PD, Smout AJ. Relationship between esophageal contraction patterns and clearance of swallowed liquid and solid boluses in healthy controls and patients with dysphagia. Neurogastroenterol Motil 2012;24:e364-e372.

19. Sweis R, Anggiansah A, Wong T, Kaufman E, Obrecht S, Fox M. Normative values and inter-observer agreement for liquid and solid bolus swallows in upright and supine positions as assessed by esophageal highresolution manometry. Neurogastroenterol Motil 2011;23:509-e198.

20. Sweis R, Anggiansah A, Wong T, Brady G, Fox M. Assessment of esophageal dysfunction and symptoms during and after a standardized test meal: development and clinical validation of a new methodol- 
ogy utilizing high-resolution manometry. Neurogastroenterol Motil 2014;26:215-228.

21. Ribolsi M, Holloway RH, Emerenziani S, Balestrieri P, Cicala M. Impedance-high resolution manometry analysis of patients with nonerosive reflux disease. Clin Gastroenterol Hepatol 2014;12:52-57.

22. Ribolsi M, Balestrieri P, Holloway RH, Emerenziani S, Cicala M. Intra-bolus pressure and esophagogastric gradient, assessed with high- resolution manometry, are associated with acid exposure and proximal migration of refluxate. Dis Esophagus 2016;29:1020-1026.

23. Ribolsi M, Balestrieri P, Biasutto D, Emerenziani S, Cicala M. Role of mixed reflux and hypomotility with delayed reflux clearance in patients with non-cardiac chest pain. J Neurogastroenterol Motil 2016;22:606612 